\title{
Heavy metals accumulation in suburban roadside plants of a tropical area (Jengka, Malaysia)
}

\author{
Fazrul Razman Sulaiman ${ }^{*}$ (D) and Huda Asilah Hamzah
}

\begin{abstract}
Introduction: This study aims to examine the uptake and translocation of $\mathrm{Cd}, \mathrm{Cu}$, $\mathrm{Fe}$, and $\mathrm{Pb}$ in different parts of three roadside plant species grown in the semi-urban of Jengka, Pahang, Malaysia.

Methods: Heavy metal concentrations were determined from various parts of Athyrium esculentum (AE), Chromolaena odorata (CO), and Lantana camara (LC). The bioconcentration factor (BCF) and translocation ratio of heavy metals from soils to plants were estimated.

Results: Fe showed the highest metal concentration determined $\left(<850 \mathrm{mg} \mathrm{kg}^{-1}\right)$, while $C d$ showed the lowest metal concentration observed $\left(<0.12 \mathrm{mg} \mathrm{kg}^{-1}\right)$ in all plants. Heavy metal concentration in the roadside plants was higher than metal determined in the same species from an uncontaminated site. Principal component analysis (PCA) suggests anthropogenic and natural sources of heavy metal. Plant roots slightly enriched by $\mathrm{Cd}$ and $\mathrm{Pb}(\mathrm{BCF}<1)$, while the leaves absorbed and accumulated $\mathrm{Cu}$ and Fe (BCF $>1$ ). The translocation ratio of four metals suggests that absorption of the three plants had the rank: root > stem > leaves.

Conclusion: The metals in the root zone transported weakly to the stem but more strongly mobilized to leaves when available in the stems. A comprehensive study of heavy metal concentration in a variety of roadside plants in the tropical area should be done in the future ensuring the precise source and translocation mechanisms.
\end{abstract}

Keywords: Bioconcentration factor, Metals, Roadside plants, Translocation ratio, Semi-urban

\section{Introduction}

Heavy metals can accumulate and migrate in the soil environment. Metal pollutants in soil may be absorbed by the plants through their roots and vascular system. Accumulation of metals in soil could affect the ecosystem safety and pose a threat to animals, plants, and human. High concentrations of metals in the plant could inhibit the ability of the plant to produce chlorophyll, increase the plant oxidative stress and weaken stomata resistance (Ashraf et al. 2011). Unnatural occurring heavy metals such as chromium $(\mathrm{Cr})$ and cadmium $(\mathrm{Cd})$ may suppress the growth of a plant, whether the pollution comes from soil or air (Street 2012). Perhaps heavy metals can enter human bodies via the food chain, leading to incremental of chronic diseases such as cancer

\footnotetext{
* Correspondence: fazrul@pahang.uitm.edu.my

Faculty of Applied Sciences, Universiti Teknologi MARA Cawangan Pahang, 26400 Bandar Tun Abdul Razak, Jengka, Pahang, Malaysia
}

(Muller and Anke 1994; Ramadan and Al-Ashkar 2007) and affecting the central nervous system, particularly in children (Zhao et al. 2009).

Plants growing at the roadside may be exposed to high levels of metal pollution, especially vehicle emissions and trace content in the air. Feng et al. (2011) suggested heavy metal from traffic emission may accumulate in roadside plants from the soil. Meanwhile, other researchers reported airborne heavy metal could be deposited and absorbed on the leafy part (Nabulo et al. 2006; Shahid et al. 2017). Cadmium (Cd), copper $(\mathrm{Cu})$, and lead $(\mathrm{Pb})$ may originate from tires, engine oil consumption, brake wear, and road surface material (Chen et al. 2010; Zhang et al. 2012; Ugolini et al. 2013). Heavy metals from traffic activities could accumulate in the soil before being absorbed by plant roots. Since heavy metals are resistant and stay in the plant for a long time (Boularbah et al. 2006), they may be transferred to 
humans via the food chain (Zhang et al. 2012). Bioavailability of heavy metals is primarily affected by the soil's physical-chemical properties (Liu et al. 2007) and plant species (Koz and Cevik 2014; Keshavarzi et al. 2015; Zhao and Duo 2015). Some species of roadside plants are edible while some other are used for medicinal purposes (Chandrashekara and Thasini 2016). Certain species such as Athyrium esculentum (AE) are edible (Roslan et al. 2016), and Chromolaena odorata (CO) is known to be used for medicinal purposes. Muhammad and Mustafa (1994) reported that CO could stop bleeding by pounding the leaves until fine and mixed with some saliva and applied to the wound.

Recently, researchers have focused on the significance of soil types, uptake, and accumulation of heavy metal in the natural conditions as well as in anthropogenic sites (Nabulo et al. 2006; Khan et al. 2011; Galal and Shehata 2015; Zhang et al. 2016). Interactions between different elements possibly lead to different harmful effects on an ecosystem. Many studies related to roadside plants have been done in other regions such as Thailand (Tanhan et al. 2007), Turkey (Koz et al. 2008), Nepal (Zhang et al. 2012), China (Zhang et al. 2016), and India (Rai 2016). However, limited studies have been carried out on the fully grown roadside plants specifically in a tropical suburban region. No study has been undertaken to examine metal accumulation in roadside plants in Jengka, Pahang, Malaysia. Therefore, this pilot study was performed to determine the concentration of heavy metals in selected roadside plants and to investigate the accumulation and translocation of heavy metal within the selected roadside species. This study also attempts to identify the possible sources of heavy metal in roadside plants.

\section{Methods}

\section{Sampling location}

Jengka is situated in the west of Maran district, in the state of Pahang, Malaysia. Jengka is surrounded by palm oil plantations, but in the last decades, the town center has grown to become a semi-urban area with many residential estates to cater for approximately 25,000 people. For this study, the sampling site is located at the main roadside of Jengka town $\left(03^{\circ} 46^{\prime} \mathrm{N}, 102^{\circ} 32^{\prime} \mathrm{E}\right)$ and the road was built about 30 years ago. During peak hours, this station experiences a high-traffic flow, mainly on weekdays. Figure 1 shows the sampling location (S1) for this study.

\section{Sample collection and analyses}

The roadside plants chosen for this study were Athyrium esculentum (AE), Chromolaena odorata (CO), and Lantana camara (LC) on the basis of dominant plants available in the study area. Additionally, $\mathrm{AE}$ and $\mathrm{CO}$ species are edible and used for medicinal purposes by the local community. Each plant was sampled with replicates
( $n=9)$ within $30 \mathrm{~m}$ of the roadside. No bigger plant species available, and the sampling location was surrounded by buildings. Nabulo et al. (2006) suggested that plants that grow within $30 \mathrm{~m}$ of the edge of a road may expose to pollutants. The corresponding soils at $0-20 \mathrm{~cm}$ in depth were also collected and then placed in a separated polyethylene bag for transportation to the laboratory. The samples were taken during the dry season, between April and May 2014. The plants were separated into roots, stems, and leaves, and then rinsed with deionized water, dried at $60{ }^{\circ} \mathrm{C}$ for $24 \mathrm{~h}$, ground up with an agate grinder, and homogenized. As a control, samples of the same species, with three replicates for each, were collected from an uncontaminated area, away from significant human activities such as traffic, and treated the same way as the roadside plant samples.

A microwave digestion procedure was used. About $0.5-3.0 \mathrm{~g}$ of the homogenized samples were digested under pressure in Teflon vessels with $6 \mathrm{~mL}$ of nitric acid $\left(\mathrm{HNO}_{3}\right)$ and $1 \mathrm{~mL}$ of perchloric acid $\left(\mathrm{HClO}_{4}\right)$. On completion of the digestion and after adequate cooling, solutions were filtered through a membrane filter paper of $0.45 \mu \mathrm{m}$ pore size (Whatman Millipores, Clifton, NJ, USA) and made up to $50 \mathrm{~mL}$ with $1 \% \mathrm{HNO}_{3}$. The same procedure was utilized for soil samples. $\mathrm{Cd}, \mathrm{Cu}, \mathrm{Fe}$, and $\mathrm{Pb}$ concentration were analyzed using graphite furnace atomic absorption spectrometry (GFAAS, Perkin Elmer PinAAcle 900T, PerkinElmer Inc., Waltham, USA).

\section{Quality control and assurance}

The relative standard deviation (RSD) for each metal repeated analysis was maintained below $5 \%$. The detection limits for all elements were $0.4 \mathrm{mg} \mathrm{kg}^{-1}$ for $\mathrm{Cd}, 5 \mathrm{mg} \mathrm{kg}^{-1}$ for $\mathrm{Pb}, 30 \mathrm{mg} \mathrm{kg}^{-1}$ for $\mathrm{Cu}$, and $850 \mathrm{mg} \mathrm{kg}^{-1}$ for $\mathrm{Fe}$. $\mathrm{A}$ spiked sample using a known amount of metal standard was examined via acid digestion for verification of the accuracy of the analytical procedure. Recoveries of the heavy metals ranged between 85 and $110 \%$. All reagents used were analytical reagent grade. A pre-cleaning regime, i.e., acid washed was applied for each glassware apparatus prior to use. High purity water (water sensitivity $\sim 18.2 \mathrm{Mohms} \cdot \mathrm{cm}$ at $25^{\circ} \mathrm{C}$; Millipore, MA, USA) was used throughout this study for laboratory applications including reagents, blanks, and standard preparation.

\section{Data analyses}

\section{Heavy metal accumulating capacities}

The bioconcentration factor (BCF) and translocation factor (TF) were estimated for heavy metal uptake capacities of plants. Bioconcentration factor (BCF) is the ratio of the content of metals in various parts of a plant to that in the soil (Liu et al. 2009). If the BCF $\leq 1.00$, it indicates the plant can only absorb but not accumulate metal. The plant may have potential to accumulate metal 


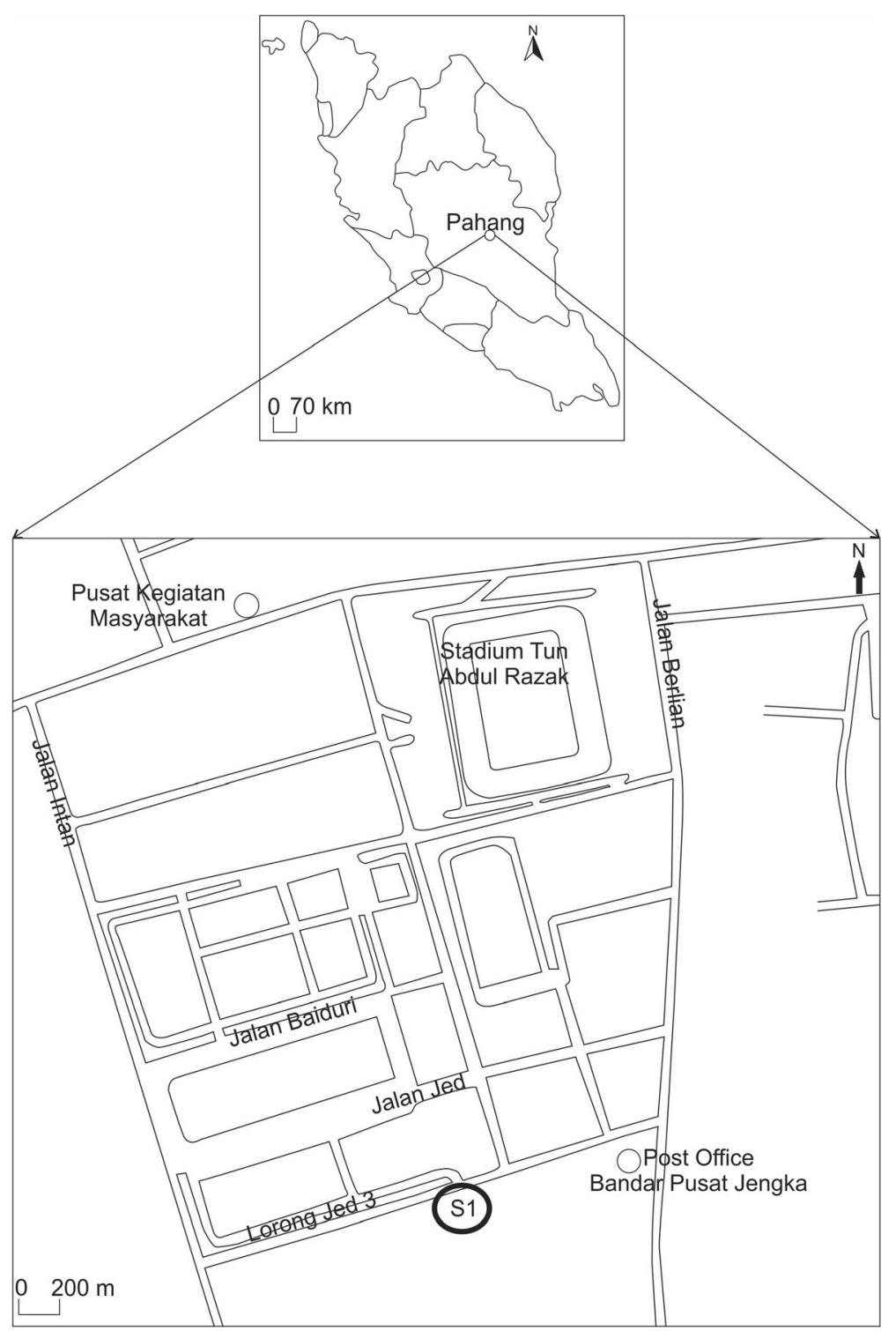

Fig. 1 Location of study area and sampling site (S1) for roadside sample

if the BCF $>1.00$ (Liu et al. 2009). BCF is calculated using the following formula:

$$
\mathrm{BCF}=C_{\text {plant }} / C_{\text {soil }}
$$

where $C_{\text {plant }}$ is the concentration of metal in plant part and $C_{\text {soil }}$ is the concentration of metal in soil. In addition, TF, the translocation capacity from the root to the aboveground part of the plant (stem and leaves), was estimated using the following equation;

$$
\mathrm{TF}=C_{\text {stem or leaves }} / C_{\text {root or stem }}
$$

$C_{\text {stem or leaves }}$ is the concentration of metal in stem or

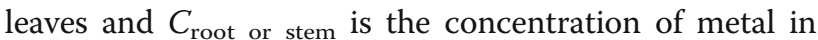
root or stem.

\section{Enrichment factor and contamination factor}

Enrichment factor (EF) was measured by the ratio of elemental concentration $\left(C_{x}\right)$ over the concentration of reference element $\left(C_{\mathrm{Fe}}\right)$ in the sample divided by the ratio of elemental concentration $\left(C_{x}\right)$ over the concentration of reference element $\left(C_{\mathrm{Fe}}\right)$ in control as in Eq. 3;

$$
\mathrm{EF}=\frac{C_{x} / C_{\mathrm{Fe}}(\text { sample })}{C_{x} / C_{\mathrm{Fe}}(\text { control })}
$$

The control used in EF estimation was the same plant species from the uncontaminated area. The reference element used for EF determination was Fe. A value of EF above ten is identified as anthropogenic sources of pollution whereas an EF value below ten is recognized as 
natural sources pollution (Fagbote and Olanipekun 2010). $\mathrm{Lu}$ et al. (2014) suggests the degree of metal enrichment (EF value) as minimal $(\mathrm{EF} \leq 2)$, moderate $(2<\mathrm{EF} \leq 5)$, significant $(5<\mathrm{EF} \leq 20)$, and very high $(\mathrm{EF}>20)$.

The contamination factor (CF) was calculated by the ratio between the metals in the samples and the background value of the corresponding metal (Rajmohan et al. 2014). In this study, the CF calculation used the control sample (taken from the uncontaminated site) as the background value. The contamination factor was classified into four groups by Pekey et al. (2004), including low $(\mathrm{CF}<1)$, moderate $(1 \leq \mathrm{CF} \leq 3)$, considerable $(3 \leq$ $\mathrm{CF} \leq 6)$, and very high $(\mathrm{CF}>6)$.

\section{Statistical analysis}

The collected data were analyzed using Statistical Package for Social Sciences (SPSS version 21.0), and the statistical significance level was defined at $p<0.05$. Principal component analysis (PCA), a multivariate analysis technique, has been applied to determine the possible sources of heavy metal in roadside plants. An eigenvalue greater than one was chosen to obtain the significant value for the principal component. Mustapha (2012) suggests the factor loading after rotation can be classified as strong $(>0.75)$, moderate $(0.50-0.75)$, or weak $(<$ 0.50). The absolute principal component score (APCS) method was utilized to quantify the contribution of each source to specific measured pollutants (Khan et al. 2010). The factor scores for the artificial sample were subtracted from those of each true sample to estimate the APCS (Mohamad et al. 2016). Then, the multiple linear regression (MLR) procedure was applied to estimate the source contribution, using metal concentration as a dependent variable and absolute score factors as independent variables. According to Mohamad et al. (2016), the PCA-APCS is capable to identify different sources and composition without any prior knowledge about the sources.

\section{Results and discussion \\ Metal concentration}

The concentration of metals in different parts of $\mathrm{AE}, \mathrm{CO}$, LC, and soil samples collected from the study area are shown in Table 1. Roots tend to have a higher concentration of metals compared to the stems and leaves (Zhao and Duo 2015; Juen et al. 2014). Roots act as a barrier for metal translocation and protect stem and other plant parts from metal contamination (Liu et al. 2009). However, this study found $\mathrm{Cu}$ and $\mathrm{Fe}$ concentrations in stems and leaves to be higher than those in the roots of all plants studied.

From Table 1, all plants showed the same Fe distribution with increment concentration order of roots $<$ stems $<$ leaves. For sample collected from the roadside, Fe concentration from roots had a range from $265.30 \pm 83.72$ to
$496.50 \pm 27.01 \mathrm{mg} \mathrm{kg}^{-1}$, while stems and leaves were ranged from $322.25 \pm 18.87$ to $580.50 \pm 13.29 \mathrm{mg} \mathrm{kg}^{-1}$ and $545.15 \pm 31.32$ to $841.60 \pm 8.62 \mathrm{mg} \mathrm{kg}^{-1}$, respectively. As for the control sample, Fe concentration also showed the same trend of increment from root to leaves except for $\mathrm{AE}$ species. Fe will be absorbed by the roots in the form of free ions. From the roots, this element can be detected in the stems since for the transferring process of the minerals to the shoot has to pass through xylem and phloem that located in the stems. Fe acts as an important element in a photosynthetic process that occurs in the chloroplast. Since chloroplast is found in the green part of the leaves, Fe will mostly accumulate there. The high Fe concentration indicates that there are metabolic activities that happen in the leaves. All of the processes needed for photosynthesis such as absorption of sunlight and transpiration will increase the concentration of $\mathrm{Fe}$ in the leaves (Frossard et al. 2000).

Leaves contain the highest concentration of $\mathrm{Cu}$ followed by roots and stems for all plants in the roadside sample (Table 1). On average, LC contains the highest $\mathrm{Cu}$ concentration $\left(>21 \mathrm{mg} \mathrm{kg}^{-1}\right)$, followed by $\mathrm{CO}\left(>12 \mathrm{mg} \mathrm{kg}^{-1}\right)$. The lowest $\mathrm{Cu}$ concentration was discovered in all parts of $\mathrm{AE}$ with the concentration of more than $10 \mathrm{mg} \mathrm{kg}$. The control samples showed the same trend of $\mathrm{Cu}$ concentration, however, with lower concentration. According to Tanhan et al. (2007) and Aiyesanmi et al. (2012), CO, which also known as Siamese weed, has a high ability to absorb heavy metal. Since it is a widely growing plant and resistant in the environment, the level of absorption of heavy metal will also increase (Aiyesanmi et al. 2012). Nonetheless, $\mathrm{Cu}$ is required by the plant tissue for the growth process.

In this study, roots showed the highest concentration of $\mathrm{Pb}$ ranging from $2.64 \pm 0.43 \mathrm{mg} \mathrm{kg}^{-1}$ to $3.79 \pm 0.19 \mathrm{mg} \mathrm{kg}^{-1}$ for roadside sample and from $0.50 \pm 0.11$ to $1.00 \pm$ $0.05 \mathrm{mg} \mathrm{kg}^{-1}$ for control sample as seen in Table 1 . The concentration of $\mathrm{Pb}$ from plant stems ranged from $0.33 \pm 0.04$ to $2.25 \pm 0.03 \mathrm{mg} \mathrm{kg}^{-1}$ and leaves were $0.26 \pm 0.03$ to $2.86 \pm 0.15 \mathrm{mg} \mathrm{kg}^{-1}$ for the roadside sample. Meanwhile, for the control sample, $\mathrm{Pb}$ concentration in stems was $0.45 \pm 0.03$ to $0.61 \pm 0.08 \mathrm{mg} \mathrm{kg}^{-1}$ and in leaves were $0.31 \pm 0.03$ to $0.35 \pm 0.02 \mathrm{mg} \mathrm{kg}^{-1}$. Pb has a long soil retention time and can stay in the soil for about 150 to 5000 years (Shaw 1990). Therefore, the probability for this metal to be absorbed will become higher. $\mathrm{Pb}$ does not naturally occur in the plants and can be very toxic if being consumed in high dose (Tuzen 2003). The high level of $\mathrm{Pb}$ concentration in all part of plants is primarily caused by the accumulation in the soil. The anthropogenic activities such as vehicle emissions (residual from the exhaust, tire, and brake wear) occur around the area perhaps enhancing the soil $\mathrm{Pb}$ 
Table 1 Heavy metal concentrations (mean \pm standard deviation) in Athyrium esculentum (AE), Chromolaena odorata (CO), Lantana camara $(\mathrm{LC})$, and soils for roadside plants and control

\begin{tabular}{|c|c|c|c|c|c|c|}
\hline & $\mathrm{AE}\left(\mathrm{mg} \mathrm{kg}^{-1}\right)$ & $\mathrm{CO}\left(\mathrm{mg} \mathrm{kg}^{-1}\right)$ & $\mathrm{LC}\left(\mathrm{mg} \mathrm{kg}^{-1}\right)$ & Soil $\left(\mathrm{mg} \mathrm{kg}^{-1}\right)$ & Malaysia Food Regulations (1985) $\left(\mathrm{mg} \mathrm{kg}^{-1}\right)$ & FAO/WHO (2016) $\left(\mathrm{mg} \mathrm{kg}^{-1}\right)$ \\
\hline \multicolumn{7}{|l|}{ Roadside } \\
\hline $\mathrm{Fe}$ & & & & $275.6 \pm 0.31$ & $N A$ & $N A$ \\
\hline Leaves & $545.1 \pm 31.3$ & $749.8 \pm 10.6$ & $841.6 \pm 8.6$ & & & \\
\hline Stems & $322.2 \pm 18.8$ & $580.5 \pm 13.3$ & $570.2 \pm 41.8$ & & & \\
\hline Roots & $265.3 \pm 83.7$ & $401.2 \pm 30.3$ & $496.5 \pm 27.0$ & & & \\
\hline $\mathrm{Cu}$ & & & & $9.50 \pm 0.12$ & $N A$ & $N A$ \\
\hline Leaves & $18.50 \pm 1.83$ & $23.35 \pm 2.89$ & $26.85 \pm 0.77$ & & & \\
\hline Stems & $10.85 \pm 0.77$ & $12.35 \pm 1.62$ & $25.10 \pm 0.71$ & & & \\
\hline Roots & $17.05 \pm 3.32$ & $21.60 \pm 1.27$ & $21.65 \pm 2.75$ & & & \\
\hline $\mathrm{Pb}$ & & & & $4.60 \pm 0.03$ & 2 & 0.3 \\
\hline Leaves & $0.26 \pm 0.03$ & $0.33 \pm 0.06$ & $2.86 \pm 0.15$ & & & \\
\hline Stems & $0.33 \pm 0.04$ & $0.69 \pm 0.07$ & $2.25 \pm 0.03$ & & & \\
\hline Roots & $3.79 \pm 0.19$ & $2.64 \pm 0.43$ & $3.05 \pm 0.18$ & & & \\
\hline $\mathrm{Cd}$ & & & & $0.32 \pm 0.01$ & 1 & 0.2 \\
\hline Leaves & $0.01 \pm 0.01$ & $0.01 \pm 0.00$ & $0.09 \pm 0.01$ & & & \\
\hline Stems & $0.02 \pm 0.00$ & $0.01 \pm 0.00$ & $0.09 \pm 0.01$ & & & \\
\hline Roots & $0.08 \pm 0.03$ & $0.06 \pm 0.01$ & $0.11 \pm 0.00$ & & & \\
\hline \multicolumn{7}{|l|}{ Control } \\
\hline $\mathrm{Fe}$ & & & & $355 \pm 0.81$ & $N A$ & NA \\
\hline Leaves & $250 \pm 15.1$ & $300 \pm 11.1$ & $350 \pm 10.4$ & & & \\
\hline Stems & $150 \pm 22.8$ & $200 \pm 8.5$ & $305 \pm 14.5$ & & & \\
\hline Roots & $100 \pm 12.5$ & $150 \pm 6.7$ & $200 \pm 13.6$ & & & \\
\hline $\mathrm{Cu}$ & & & & $20.0 \pm 0.92$ & $N A$ & $N A$ \\
\hline Leaves & $8.00 \pm 0.10$ & $12.00 \pm 0.70$ & $16.00 \pm 2.2$ & & & \\
\hline Stems & $5.20 \pm 0.69$ & $10.00 \pm 0.89$ & $14.50 \pm 0.90$ & & & \\
\hline Roots & $7.00 \pm 0.43$ & $11.70 \pm 0.56$ & $14.00 \pm 0.15$ & & & \\
\hline $\mathrm{Pb}$ & & & & $1.80 \pm 0.30$ & 2 & 0.3 \\
\hline Leaves & $0.35 \pm 0.02$ & $0.41 \pm 0.01$ & $0.80 \pm 0.03$ & & & \\
\hline Stems & $0.45 \pm 0.03$ & $0.61 \pm 0.08$ & $0.50 \pm 0.12$ & & & \\
\hline Roots & $0.50 \pm 0.11$ & $0.70 \pm 0.04$ & $0.80 \pm 0.05$ & & & \\
\hline $\mathrm{Cd}$ & & & & $0.15 \pm 0.02$ & 1 & 0.2 \\
\hline Leaves & $0.005 \pm 0.00$ & $0.005 \pm 0.01$ & $0.015 \pm 0.00$ & & & \\
\hline Stems & $0.005 \pm 0.00$ & $0.005 \pm 0.00$ & $0.010 \pm 0.00$ & & & \\
\hline Roots & $0.02 \pm 0.01$ & $0.01 \pm 0.00$ & $0.025 \pm 0.01$ & & & \\
\hline
\end{tabular}

$N A$ no available standards

concentration (Aiyesanmi et al. 2012). Malaysia has banned the use of lead in gasoline around 20 years ago. However, the leftover $\mathrm{Pb}$ can still be traced.

All of the three plants have a higher concentration of $\mathrm{Cd}$ in roots $\left(\leq 0.11 \pm 0.00 \mathrm{mg} \mathrm{kg}^{-1}\right)$ than stems $\left(\leq 0.09 \pm 0.01 \mathrm{mg} \mathrm{kg}^{-1}\right)$ and leaves $\left(\leq 0.09 \pm 0.01 \mathrm{mg} \mathrm{kg}^{-1}\right)$ as seen in Table 1 for the roadside sample. For the control sample, the same trend is observed. Cd could occur naturally when it is bound with another metal
(Khan et al. 2011). The LC species showed high Cd concentrations in all parts compared to $\mathrm{AE}$ and $\mathrm{CO}$ plants. Perhaps LC has more ability to absorb $\mathrm{Cd}$ from soils than other plants (Dissanayake et al. 2002). If the AE and CO plants are consumed, e.g., for medicinal purposes, they must be considered safe based on the limitation set up by Malaysian Food Regulations (1985) except for $\mathrm{Pb}$ in roots for the roadside sample (Table 1). For LC, the $\mathrm{Pb}$ content in all parts of this plant exceeded the guideline value; 
fortunately, this is a non-edible species. However, all plants exceeded the recommended value for $\mathrm{Pb}$ fixed by Food and Agriculture Organization/World Health Organization (FAO/WHO 2016) except for leaves of AE species in the roadside sample.

\section{Comparison with previous studies}

Table 2 shows the comparison between heavy metals in roadside plants obtained in this study with heavy metals in roadside plants reported from previous studies. The $\mathrm{Pb}$ and $\mathrm{Cd}$ concentrations were lower than that of roadside plant samples collected from Kanchanaburi, Thailand (Tanhan et al. 2007), Akure, Nigeria (Aiyesanmi et al. 2012), and Pontian, Malaysia (Roslan et al. 2016). However, $\mathrm{Fe}$ and $\mathrm{Cu}$ concentrations were higher than in the other study area in India (Rai 2016). This may be due to different anthropogenic factors such as industrial activities, population and settlement patterns, and differences in traffic density. The levels also depend on the soil concentrations of those heavy metals that are available naturally. Furthermore, heavy metal concentrations in roadside plants were higher than the concentrations in the same plant species from the uncontaminated area. This gives us an indication that human activities (traffic) do influence the metal concentration in the plants. Perhaps high-metal concentrations were found at those sampling sites where human activities are more intense.

\section{Enrichment factor (EF) and contamination factor (CF)}

Table 3 shows the EF level of each metal from three different roadside plant species. Results showed that the EF value is less than ten, with values less than two indicative minimal enrichment. LC species showed the highest enrichment for $\mathrm{Cd}$ (2.59), followed by $\mathrm{Pb}$ (1.74) and $\mathrm{Cu}$ (0.74). $\mathrm{AE}$ and $\mathrm{CO}$ species also revealed the rank of $\mathrm{EF}$ value $\mathrm{Cd}>\mathrm{Pb}>\mathrm{Cu}$. Table 3 indicates the $\mathrm{CF}$ in the study area ranges between 2.23 and 2.66 for $\mathrm{Fe}, 1.65$ and 2.29
Table 3 Enrichment factor (EF) and contamination factor (CF) for selected metals in different roadside plants species

\begin{tabular}{lllll}
\hline Roadside plant & $\mathrm{Fe}$ & $\mathrm{Cu}$ & $\mathrm{Pb}$ & $\mathrm{Cd}$ \\
\hline Enrichment factor & & & & \\
AE & 1 & 1.01 & 1.49 & 1.76 \\
CO & 1 & 0.64 & 0.80 & 1.50 \\
LC & 1 & 0.74 & 1.74 & 2.59 \\
Contamination factor & & & & \\
AE & 2.26 & 2.29 & 3.37 & 4.00 \\
CO & 2.66 & 1.70 & 2.15 & 4.00 \\
LC & 2.23 & 1.65 & 3.88 & 5.80 \\
\hline
\end{tabular}

AE Athyrium esculentum, CO Chromolaena odorata, LC Lantana cámara

for $\mathrm{Cu}, 2.15$ and 3.88 for $\mathrm{Pb}$, and 4.0 and 5.8 for $\mathrm{Cd}$. The roadside plant samples in this study are range from moderate contamination to considerable contamination of selected metal based on Pekey et al. (2004) classification. This gives a hint significant portion of metals which have originated from non-crustal source or anthropogenic processes, especially for $\mathrm{Pb}$ and $\mathrm{Cd}$.

\section{Source identification of heavy metal}

Table 4 shows the results of the varimax rotated factor analysis for heavy metal in roadside plants. Two key factors were identified in the overall dataset $(94.39 \%$ of total variance). Factor 1 with $57.86 \%$ of the total variance showed a strong loading for $\mathrm{Cd}$ and $\mathrm{Pb}$. These elements can be categorized as originating from anthropogenic sources such as motor vehicles (Aiyesanmi et al. 2012; Zhang et al. 2012; Khan et al. 2011; Chen et al. 2010; Koz et al. 2010; Tuzen 2003). Moreover, the sampling point was located at the main roadside of Jengka town which is exposed to heavy traffic activities especially on weekdays. The second factor (factor 2) was found to show a strong factor loading for $\mathrm{Cu}$ and $\mathrm{Fe}$ with $36.53 \%$ of the total variance. Fe is an element which is present in soil and the

Table 2 Comparison of metal concentrations $\left(\mathrm{mg} \mathrm{kg}^{-1}\right)$ in roadside plants from this study with data available from some previous studies

\begin{tabular}{|c|c|c|c|c|c|c|c|}
\hline \multirow[t]{2}{*}{ Location } & \multirow[t]{2}{*}{ Area } & \multirow[t]{2}{*}{ Species } & \multirow{2}{*}{$\begin{array}{l}\text { Heavy } \\
\mathrm{Fe}\end{array}$} & \multirow{2}{*}{$\begin{array}{l}\text { metal } \\
\mathrm{Cu}\end{array}$} & \multicolumn{2}{|c|}{$\left(\mathrm{mg} \mathrm{kg}^{-1}\right)$} & \multirow[t]{2}{*}{ References } \\
\hline & & & & & $\overline{\mathrm{Pb}}$ & $\mathrm{Cd}$ & \\
\hline \multirow[t]{6}{*}{ Jengka, Malaysia } & \multirow[t]{3}{*}{ Suburban } & $\mathrm{AE}$ & 1132.7 & 46.4 & 4.39 & 0.12 & \multirow[t]{3}{*}{ This study } \\
\hline & & $\mathrm{CO}$ & 1731.5 & 57.3 & 3.66 & 0.08 & \\
\hline & & LC & 1908.3 & 73.6 & 8.16 & 0.29 & \\
\hline & \multirow[t]{3}{*}{ Rural (control) } & $A E$ & 500 & 20.2 & 1.3 & 0.03 & \multirow[t]{3}{*}{ This study } \\
\hline & & $\mathrm{CO}$ & 650 & 33.7 & 1.7 & 0.02 & \\
\hline & & LC & 855 & 44.5 & 2.1 & 0.05 & \\
\hline Ramrikawn, India & Suburban & LC & 20 & 15 & NA & $N A$ & Rai (2016) \\
\hline Pontian, Malaysia & Suburban & $\mathrm{AE}$ & NA & $N A$ & NA & 0.48 & Roslan et al. (2016) \\
\hline Akure, Nigeria & Suburban & $\mathrm{CO}$ & $N A$ & $N A$ & 30.9 & NA & Aiyesanmi et al. (2012) \\
\hline Kanchanaburi, Thailand & Suburban & $\mathrm{CO}$ & $N A$ & $N A$ & 38.1 & 0.9 & Tanhan et al. (2007) \\
\hline
\end{tabular}

NA no available data, AE Athyrium esculentum, CO Chromolaena odorata, LC Lantana cámara 
Table 4 Factor loading for heavy metal after varimax rotation using PCA

\begin{tabular}{lll}
\hline Metal & Factor 1 & Factor 2 \\
\hline $\mathrm{Fe}$ & -0.18 & 0.95 \\
$\mathrm{Cu}$ & 0.51 & 0.81 \\
$\mathrm{Cd}$ & 0.96 & 0.12 \\
$\mathrm{~Pb}$ & 0.97 & -0.05 \\
Eigenvalues & 2.31 & 1.46 \\
Variability (\%) & 57.86 & 36.53 \\
Cumulative (\%) & 57.86 & 94.39 \\
\hline
\end{tabular}

Factors in italics indicated a strong factor loading

earth's crust (Shaw 1990; Koz et al. 2008), while Cu could come from traffic activities (Ugolini et al. 2013). Therefore, metal elements in factor 2 perhaps contributed by a mixture of natural and anthropogenic origin.

The absolute factor scores were regressed against metal concentration using MLR analysis to apportion the percentage mass contribution of each identified source. The contribution of the possible sources of different elements in the plant is presented in Fig. 2. The main composition was dominated by natural and was coupled with road dust sources with $85 \%$ contribution. The other source was road dust due to motor vehicle activities (15\%). This analysis suggests that the possible sources contributing to the range of metal elements in the roadside plant was traffic activities, apart from the natural crust.

\section{Bioconcentration factor (BCF)}

Figure 3 shows the $\mathrm{BCF}$ values for $\mathrm{Cd}, \mathrm{Cu}, \mathrm{Fe}$, and $\mathrm{Pb}$ in all plants. For the roadside samples, BCF value of $\mathrm{Cu}$ in the roots, stems, and leaves for all plants exceeded value 1.00. This indicates all parts, roots, stems, and leaves can absorb and accumulate $\mathrm{Cu}$. A similar pattern has been observed for $\mathrm{Fe}(\mathrm{BCF}>1)$. It is expected as $\mathrm{Cu}$ and $\mathrm{Fe}$ concentrations in the soil were high. Moreover, these elements, $\mathrm{Cu}$ and $\mathrm{Fe}$, are necessary for plant growth and

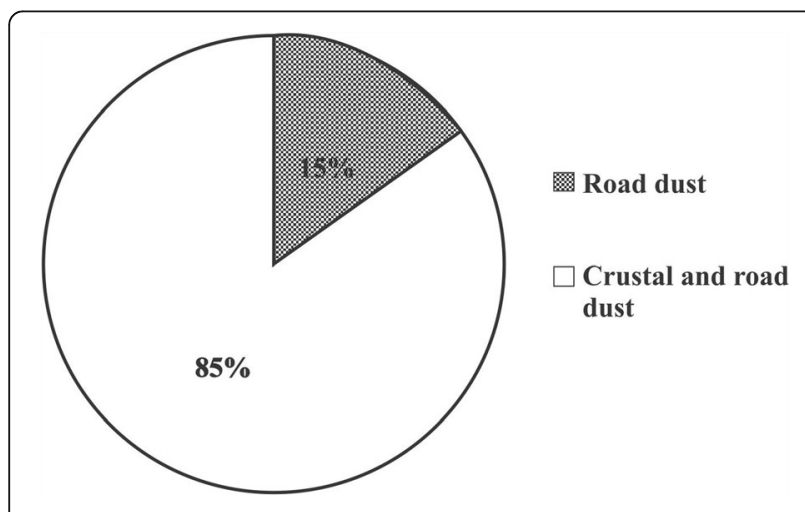

Fig. 2 Contribution of possible sources of metal elements in roadside plants physiology (Shuman 2004; Bose and Bhattacharyya 2008). Nevertheless, for the control sample, BCF values for $\mathrm{Cu}$ and $\mathrm{Fe}$ were lower than 1.00 except for leaves part of LC species (Fig. 3b).

$\mathrm{BCF}$ values for $\mathrm{Pb}$ in the roots, stems and leaves of $\mathrm{AE}$, $\mathrm{CO}$, and LC were less than 1.00 (Fig. 3). These results have suggested that $\mathrm{Pb}$ bioavailability is low, and the plants can only absorb but do not accumulate it. The data for $\mathrm{AE}$ species from the previous study was limited; thus, this study tries to compare with other edible species. This finding agrees with previous studies on Oryza sativa by Liu et al. (2007) and Juen et al. (2014) but contradicts a study on CO species by Tanhan et al. (2007). Pb is relatively stable in soil (Khairiah et al. 2009). The presence of $\mathrm{Pb}$ in soil is due to natural soil deposits (Sulaiman et al. 2016). According to Juen et al. (2014), Pb has a tendency to bind with oxides of $\mathrm{Fe}$ and $\mathrm{Mn}$ in soils. Therefore, $\mathrm{Pb}$ may be available in the form of Fe oxides especially for the roadside sample (Fig. 3a) compared to the control sample (Fig. 3b). It is important to note that the roadside sample was collected from a suburban area; thus, the soil was likely to have received anthropogenic $\mathrm{Pb}$ originating from vehicles and other urban activities. Moreover, traffic density has a strong correlation with $\mathrm{Pb}$ pollution in roadside soils (Walraven et al. 2014).

$\mathrm{BCF}$ values of $\mathrm{Cd}$ in all parts of all plants were less than 1.00 (Fig. 3). These findings suggest that all plants parts can absorb $\mathrm{Cd}$ and do not accumulate it. Plant roots seem to absorb more $\mathrm{Cd}$ than stems and leaves. This is in line with other study suggesting trace metals are retained in the lower part of plants (Bonanno 2013). Galal and Shehata (2015) reported high bioaccumulation of $\mathrm{Cd}$ in roadside plants closer to a road. Perhaps $\mathrm{Cd}$ uptake was correlated with organic matter (Zarcinas et al. 2004; Liu et al. 2009) as well as soil pH (Galal and Shehata 2015). The roadside sample has a higher BCF value than the control sample, as expected. The roadside sample was exposed to significant anthropogenic activities which possibly contribute to the increment of metal concentration in the soil and plants.

\section{Translocation factor (TF)}

Translocation ratios from root to stem and from stem to leaves were calculated for each metal. Figure 4 shows translocation ratios of $\mathrm{Cd}, \mathrm{Cu}, \mathrm{Fe}$, and $\mathrm{Pb}$ in $\mathrm{AE}, \mathrm{CO}$, and $\mathrm{LC}$ species for roadside and control samples. Both roadside sample and control sample perhaps show similar TF trend. All plants have translocation ratios of metal below 1.00 from roots to stems except Fe. LC showed a translocation ratio of $\mathrm{Cu}$ slightly more than 1.00 from roots to stems. All metals translocate from stems to leaves more than that from roots to stems. This indicates these metals in the root zone transported weakly to the stem but somehow easily mobilized to leaves when they are available in the stems. 

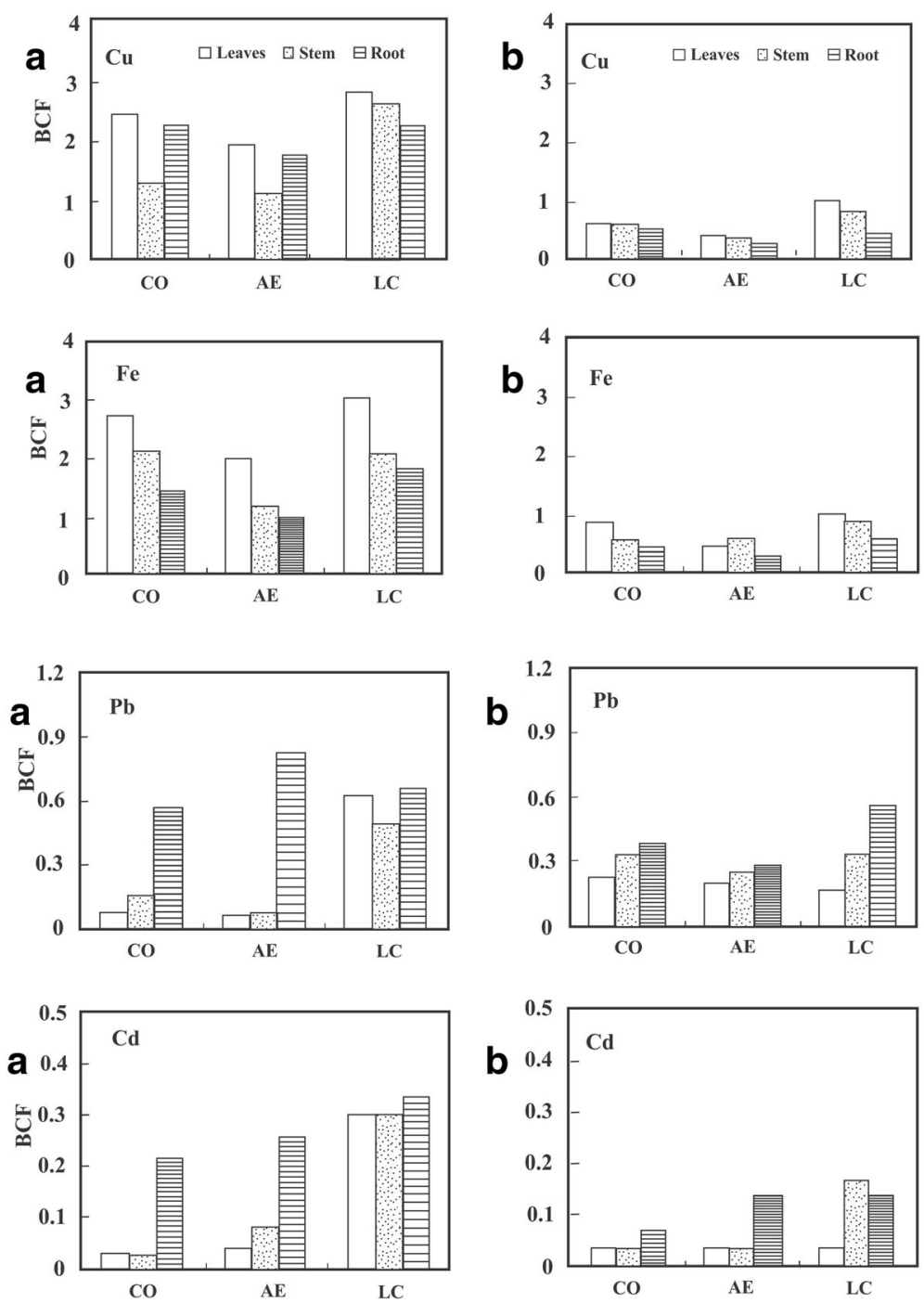

Fig. 3 Bioconcentration factors of $\mathrm{Cd}, \mathrm{Cu}, \mathrm{Fe}, \mathrm{Pb}$ for Athyrium esculentum (AE), Chromolaena odorata (CO) and Lantana camara (LC) for a roadside sample, and $\mathbf{b}$ control sample

For these four metals, absorption of the three plants had the rank: root $>$ stem $>$ leaves. Metals were transported weakly into the stems and leaves, and roots act as the barrier for the contamination. Due to a lack of previous studies for AE and LC species, the results were compared to other species. The results are in agreement with previous studies performed by Liu et al. (2009) on winter wheat, Liu et al. (2007) and Juen et al. (2014) on paddy plant, and Tanhan et al. (2007) on Siamese weed (CO). Perhaps different chemical properties of metal induce different accumulation and translocation capacity (Liu et al. 2009).

It worth noting that plant could receive heavy metal from atmospheric deposition. Shahid et al. (2017) found that heavy metal could be absorbed by leaves directly from the air, however, depending on various factors. This includes the adsorption capacity and physical characteristics of the plant's leaves as well as the plant species. In this present study, the findings suggest that the mobility of heavy metals from the soil to plant is equally important as the metal airborne absorption on the leafy part of a plant. Perhaps different location will have a different heavy metal accumulating ability. Besides, the local meteorological factors also could influence the heavy metal mobility such as precipitation trend and wind speed. The sampling point is not covered by other bigger plant species and surrounded by buildings, hence, affecting the metal absorption by the roadside plants.

\section{Conclusions}

Plant roots are slightly enriched with $\mathrm{Cd}$ and $\mathrm{Pb}$ from the soil, while the leaves absorb and accumulate $\mathrm{Cu}$ and Fe. PCA shows that heavy metals originated from both 

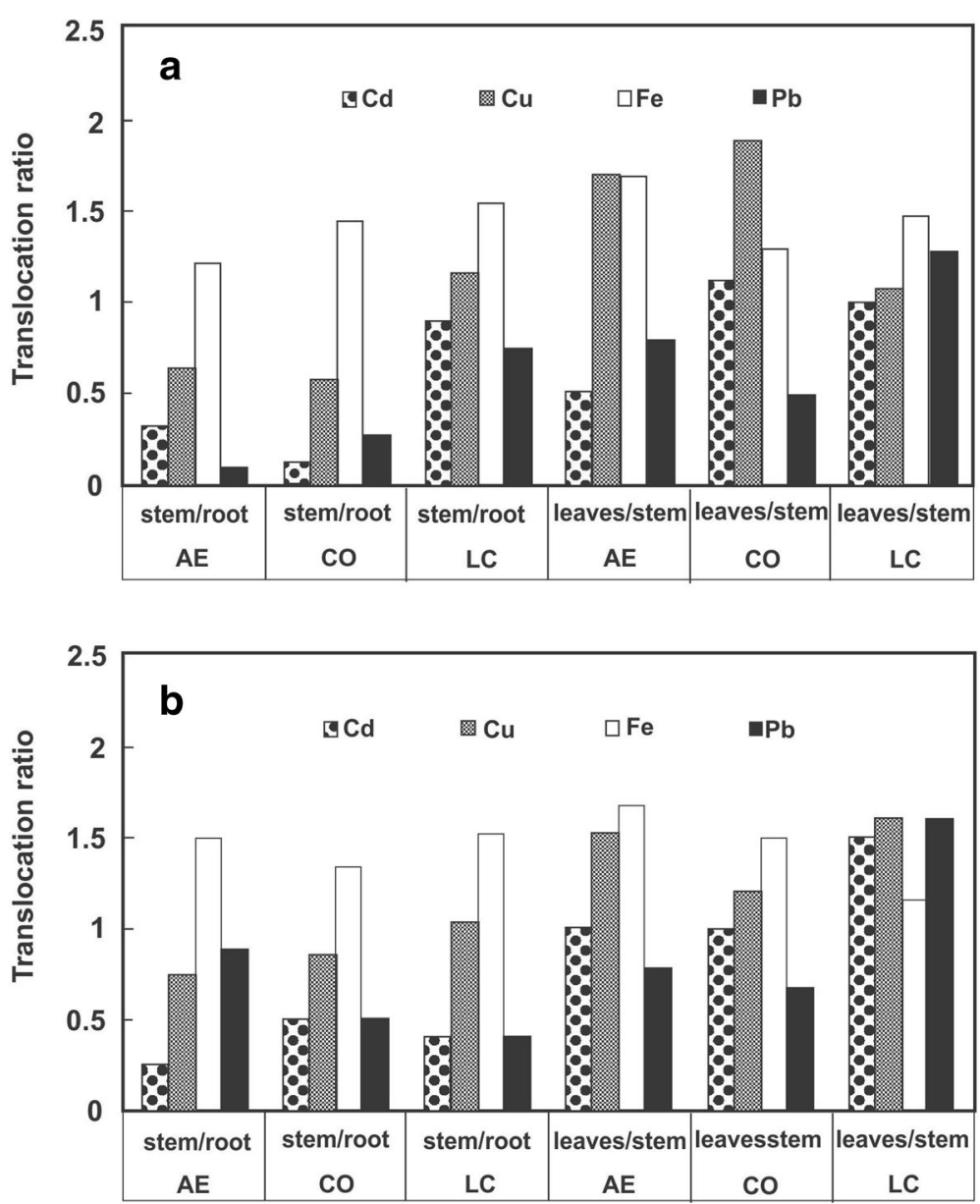

Fig. 4 Translocation ratios of metals from roots to stems and stems to leaves of Athyrium esculentum (AE), Chromolaena odorata (CO), and Lantana camara (LC) for $\mathbf{a}$ roadside sample and $\mathbf{b}$ control sample

anthropogenic and natural sources. Although this study may be limited in terms of sample size and sample collection time frame (dry season), it suggests roadside plant transport heavy metals from stems to leaves more readily than from roots to stems. This indicates that metals in the root zone are transported weakly to the stem but easily mobilized to leaves when available in the stems. A lab-based study could be possible ensuring the metal accumulation and transportation mechanism within roadside plants as well as ensuring the safe level if cooked (AE species) or used for medicinal purposes (CO species) by the local resident. Perhaps next study should also consider more roadside plant species, the influence of wet and dry weather seasons, and the concentration of metal in air particulate matter and watercourse nearby the study area. Comparison between direct metal airborne deposition to plant surfaces and metal uptake from soils also need to be considered. More comprehensive monitoring from various environmental medium probably enhances our understanding of the distribution, accumulation, and sources of metal in the tropical semi-urban area.

\section{Abbreviations}

AE: Athyrium esculentum; APCS: Absolute principal component scores; BCF: Bioconcentration factor; Cd: Cadmium; CF: Contamination factor; CO: Chromolaena odorata; Cr: Chromium; Cu: Copper; EF: Enrichment factor; FAO: Food and Agriculture Organization; Fe: Iron; GFAAS: Graphite furnace atomic absorption spectrophotometer; $\mathrm{HClO}_{4}$ : Perchloric acid; $\mathrm{HNO}_{3}$ : Nitric acid; LC: Lantana camara; MLR: Multiple linear regression; Pb: Lead; PCA: Principal component analysis; TF: Translocation factor; WHO: World Health Organization

\section{Acknowledgements}

We wish to thanks Universiti Teknologi MARA Cawangan Pahang for providing all necessary research facilities, especially the laboratory instruments. Special thanks to Mr. Mohd Fauzie Idrus for assistance in the GFAAS analysis and Mr. Joshua J. Stuart for assistance with the proofreading of this manuscript.

\section{Funding}

Funding was provided by the Universiti Teknologi MARA Cawangan Pahang.

Availability of data and materials

Data collected and analyzed in this study are available from the corresponding author upon request.

\section{Authors' contributions}

The first author (FRS) designed the study, conducted the data analysis, and wrote the manuscript. The second author (HAH) collected the sample and analyzed the sample. Both authors have read and approved the final manuscript. 


\section{Ethics approval and consent to participate}

Not applicable

\section{Consent for publication}

Not applicable

\section{Competing interests}

The authors declare that they have no competing interests.

\section{Publisher's Note}

Springer Nature remains neutral with regard to jurisdictional claims in published maps and institutional affiliations.

\section{Received: 16 March 2018 Accepted: 24 July 2018}

\section{Published online: 13 August 2018}

\section{References}

Aiyesanmi AF, Okoronkwo AE, Sunday OM (2012) Lead accumulation in Siam weed (Chromolaena odorata), node weed (Synedrella nodiflora) and waterleaf (Talinum triangulare): potentially phytoremediators. Arch Appl Sci Res 4(1):360-371.

Ashraf MA, Maah J, Yusoff I (2011) Heavy metals accumulation in plants growing in ex-tin mining catchment. Int J Environ Sci Technol 8(2):401-416.

Bonanno G (2013) Comparative performance of trace element bioaccumulation and biomonitoring in the plant species Typha domingensis, Phragmites australis and Arundo donax. Ecotoxicol Environ Saf 97:124-130.

Bose S, Bhattacharyya AK (2008) Heavy metal accumulation in wheat plant grown in soil amended with industrial sludge. Chemosphere 70:1264-1272.

Boularbah A, Schwartz C, Bitton G, Aboudrar W, Ouhammou A, Morel JL (2006) Heavy metal contamination from mining sites in South Morocco: 2. Assessment of metal accumulation and toxicity in plants. Chemosphere 63(5):811-817.

Chandrashekara UM, Thasini VM (2016) Non-crop edible plants and medicinal plants in Homegarden Agroforestry System of Palakkad District, Kerala. Int J Ecol Environ Sci 42(2):183-191.

Chen X, Xia X, Zhao Y, Zhang P (2010) Heavy metal concentrations in roadside soils and correlation with urban traffic in Beijing, China. J Hazard Mater 181:640-646.

Dissanayake US, Tennakoon KU, Priyantha N (2002) Potential of two invasive plant species, Lantana camara L. and Wedelia Trilobata L. for selective heavy metal uptake. Ceylon J Sci (Bio Sci) 29:1-11.

Fagbote EO, Olanipekun EO (2010) Evaluation of the status heavy metal pollution of soil and plant (Chromolaena odorata) of Agbabu bitumen deposit area, Nigeria. Am Euras J Sci Res 5(4):241-248.

FAO/WHO WHO (Food and Agriculture Organization / World Health Organization) (2016) General standard for contaminants and toxins in food and feed. Codex Alimentarius International Food Standards. CODEX STAN 193-1995. Retrieved from http://www.fao.org/fao-who-codexalimentarius/shproxy/en/?|nk=1\&url=https\%253A\%252F\%252Fworkspace.fao. org\%252Fsites\%252Fcodex\%252FStandards\%252FCODEX\%2BSTAN\%2B1931995\%252FCXS_193e.pdf. Assessed 5 Sept 2017.

Feng J, Wang Y, Zhao J, Zhu L, Bian X, Zhang W (2011) Source attributions of heavy metals in rice plant along highway in Eastern China. J Environ Sci 23(7):1158-1164.

Frossard E, Bucher M, Machler F, Mozafar A, Hurrell R (2000) Potential for increasing the content and bioavailability of $\mathrm{Fe}, \mathrm{Zn}$ and $\mathrm{Ca}$ in plants for human nutrition. J Sci Food Agric 80:861-879.

Galal TM, Shehata HS (2015) Bioaccumulation and translocation of heavy metals by Plantago major L. grown in contaminated soils under the effect of traffic pollution. Ecol Indic 48:244-251.

Juen LY, Aris AZ, Ying LW, Haris H (2014) Bioconcentration and translocation efficiency of metals in paddy (Oryza sativa): a case study from Alor Setar, Kedah, Malaysia. Sains Malays 43:521-528.

Keshavarzi B, Moore F, Ansari M, Mehr MR, Kaabi H, Kermani M (2015) Macronutrients and trace metals in soil and food crops of Isfahan Province, Iran. Environ Monit Assess 187(1):4113

Khairiah J, Habibah HJ, Anizan I, Maimon A, Aminah A, Ismail BS (2009) Content of heavy metals in soil collected from selected paddy cultivation areas in Kedah and Perlis, Malaysia. J Appl Sci Res 5(12):2179-2188.

Khan MF, Hirano K, Masunaga S (2010) Quantifying the sources of hazardous element of suspended particulate matter aerosol collected in Yokohama, Japan. Atmos Environ 44:2646-2657.
Khan S, Khan MA, Rehman S (2011) Lead and cadmium contamination of different roadside soils and plants in Peshawar city, Pakistan. Pedosphere 21(3):351-357.

Koz B, Celik N, Cevik U (2010) Biomonitoring of heavy metals by epiphytic lichen species in Black Sea region of Turkey. Ecol Indic 10:762-765.

Koz B, Cevik U (2014) Lead adsorption capacity of some moss species used for heavy metal analysis. Ecol Indic 36:491-494.

Koz B, Cevik U, Ozdemir T, Duran C, Kaya S, Gundogduc A, Celik N (2008) Analysis of mosses along Sarp-Samsun highway in Turkey. J Hazard Mater 153:646-654.

Liu WX, Liu JW, Wu MZ, Li Y, Zhao Y, Li SR (2009) Accumulation and translocation of toxic heavy metals in winter wheat (Triticum aestivum L.) growing in agricultural soil of Zhengzhou, China. Bull Environ Contam Toxicol 82(3):343-347.

Liu WX, Shen LF, Liu JW, Wang YW, Li SR (2007) Uptake of toxic heavy metals by rice (Oryza sativa L.) cultivated in agricultural soil near Zhengzhou city, People Republic of China. Bull Environ Contam Toxicol 79:209-213.

Lu X, Zhang X, Li LY, Chen H (2014) Assessment of metals pollution and health risk in dust from nursery schools in Xi'an, China. Environ Res 128:27-34.

Malaysia Food Regulation (1985) Warta Kerajaan Malaysia, vol 29. Ministry of Health Malaysia, Kuala Lumpur.

Mohamad N, Latif MT, Khan MF (2016) Source apportionment and health risk assessment of PM10 in a naturally ventilated school in a tropical environment. Ecotoxicol Environ Saf 124:351-362.

Muhammad Z, Mustafa AM (1994) Traditional Malay medicinal plants. Penerbit Fajar Bakti, Kuala Lumpur.

Muller M, Anke M (1994) Distribution of cadmium in the food chain (soil-plant-human) of a cadmium exposed area and the health risks of the general population. Sci Total Environ 156(2):151-158.

Mustapha A (2012) Identification of anthropogenic influences on water quality of Jakara River, northwestern Nigeria. J Appl Sci Environ Sanitation 7(1):11-20.

Nabulo G, Oryem-Origa H, Diamond M (2006) Assessment of lead, cadmium, and zinc contamination of roadside soils, surface films, and vegetables in Kampala City, Uganda. Environ Res 101:42-52.

Pekey H, Karakas D, Ayberk S, Tolun L, Bakoglu M (2004) Ecological risk assessment using trace elements from surface sediments of I'zmit Bay (Northeastern Marmara Sea) Turkey. Mar Pollut Bull 48:946-953.

Rai PK (2016) Biodiversity of roadside plants and their response to air pollution in an Indo-Burma hotspot region: implications for urban ecosystem restoration. J Asia Pac Biodivers 9:47-55.

Rajmohan N, Prathapar SA, Jayaprakash M, Nagarajan R (2014) Vertical distribution of heavy metals in soil profile in a seasonally waterlogging agriculture field in Eastern Ganges Basin. Environ Monit Assess 186(9):5411-5427.

Ramadan MAE, Al-Ashkar EA (2007) The effect of different fertilizers on the heavy metals in soil and tomato plant. Aust J Basic Appl Sci 1(3):300-306.

Roslan NA, Syed Ismail SN, Praveena SM (2016) The transfer factor of cadmium in fern leaves and its potential health risk. Asia Pac Environ Occup Health J 2(2):48-57.

Shahid M, Dumat C, Khalid S, Schreck E, Xiong T, Niazi NK (2017) Foliar heavy metal uptake, toxicity and detoxification in plants: a comparison of foliar and root metal uptake. J Hazard Mater 325:36-58.

Shaw AJ (1990) Heavy metal tolerance in plants: evolutionary aspects. CRC Press, Florida.

Shuman LM (2004) Mineral nutrition. In: Wilkinson RE (ed) Plant-environment interactions. Marcel Dekker Inc, New York, pp 149-182.

Street RA (2012) Heavy metals in medicinal plant products--an African perspective. S Afr J Bot 82:67-74.

Sulaiman FR, Mustaffa NFS, Mohd-Khazaai SN (2016) Preliminary assessment of selected metals in agricultural soils in Jengka, Pahang, Malaysia. Environ Earth Sci 75(3):223.

Tanhan P, Kruatrachue M, Pokethitiyook P, Chaiyarat R (2007) Uptake and accumulation of cadmium, lead and zinc by Siam weed [Chromolaena odorata (L.) King \& Robinson]. Chemosphere 68:323-329.

Tuzen M (2003) Determination of heavy metals in soil, mushroom and plant samples by atomic absorption spectrometry. Microchem J 74:289-297.

Ugolini F, Tognetti R, Raschi A, Bacci L (2013) Quercus ilex L. as bioaccumulator for heaw metals in urban areas: effectiveness of leaf washing with distilled water and considerations on trees distance from traffic. Urban For Urban Green 12(4):576-584.

Walraven N, van Os BJH, Klaver GT, Middelburg JJ, Davies GR (2014) The lead (Pb) isotope signature, behaviour and fate of traffic-related lead pollution in roadside soils in The Netherlands. Sci Total Environ 472:888-900.

Zarcinas BA, Pongsakul P, Mclaughlin MJ, Cozens G (2004) Heavy metal in soil and crops in Southeast Asia, Thailand. Environ Geochem Health 26:359-371.

Zhang H, Zhang Y, Wang Z, Ding M, Jiang Y, Xie Z (2016) Traffic-related metal(loid) status and uptake by dominant plants growing naturally in roadside soils in the Tibetan plateau, China. Sci Total Environ 573:915-923. 
Zhang M, Yan X, Zhang F, Zeng C, Devkota LP (2012) Factorial analysis of heavy metal concentration in roadside farmland plants around Kathmandu, Nepal. Appl Mech Mater 178-181:1016-1021.

Zhao K, Zhang W, Zhou L, Liu X, XU J, Huang P (2009) Modeling transfer of heavy metals in soil-rice system and their risk assessment in paddy fields. Environ Earth Sci 59(3):519-527.

Zhao S, Duo L (2015) Bioaccumulation of cadmium, copper, zinc, and nickel by weed species from municipal solid waste compost. Pol J Environ Stud 24(1):413-417.

Submit your manuscript to a SpringerOpen ${ }^{\mathcal{O}}$ journal and benefit from:

- Convenient online submission

- Rigorous peer review

- Open access: articles freely available online

- High visibility within the field

- Retaining the copyright to your article

Submit your next manuscript at $\boldsymbol{\sim}$ springeropen.com 